\title{
PERFORMANCE OF FUZZY LOGIC AND ARTIFICIAL NEURAL NETWORK IN PREDICTION OF GROUND AND AIR VIBRATIONS
}

\author{
Mostafa Tantawy Mohamed \\ Mining \& Metallurgical Dept. Assiut University (71516)-Egypt
}

(Received January 27, 2011 Accepted March 23, 2011)

\begin{abstract}
The prediction of air and ground vibrations is an important problem in rock blasting activities. The aim of this study is to evaluate the prediction of ground and air vibrations by using intelligent networks and traditional regression model. So, fuzzy logic and artificial neural network (ANN) models have been constructed to predict peak particle velocity and air overpressure induced by blasting in Assiut Cement Company. For this purpose, the peak particle velocity, air vibrations, and charge weight per delay were recorded for 136 blast events at various distances and used for the training of the predictor models. About new 26 data sets have been used to test and validate the models. The performance, validity and capability of these models to predict were proved to be successful by statistical performance indices. These indices are variance-accounted for $(V A F)$ and root mean square error (RMSE). The results from these models asserted that, intelligent networks technologies can be precisely and effectively used for predicting the air and ground vibrations in comparison with traditional regression analysis. Also, the comparison indicated that the fuzzy logic model exhibited slightly better prediction performance and generalization than the artificial neural network in ground and air vibration prediction.
\end{abstract}

\section{INTRODUCTION}

Blasting is used as a means of fragmenting rock so that it can be excavated at mines, quarries, and Construction sites. The explosive charges produce a great amount of energy, some of which is transmitted in the form of stress waves beyond the area of the fragmented rock. The propagating stress waves travel in the rock and soil and produce ground vibrations that have the potential to cause damage to structures in the vicinity of the blast. Only 20-30\% of explosive energy is utilized for fragmenting the rock and the rest wasted away in the form of ground vibration, air blast, noise, fly rock, back breaks, etc. Among them, air and ground vibration is considered to have the most damaging effect. A number of predictor equations have been proposed by various researchers to predict air and ground vibrations prior to blasting. Still, it is difficult to recommend any one predictor for a particular ground condition because air and ground vibrations are influenced by a number of parameters. These parameters are either controllable or non-controllable such as blast geometry, explosive types, rock strength properties, rock geology and climate conditions, etc..(1,2)

If an unusual noise or uncertainties exists in the measured data of vibrations, statistical models have difficulty in making accurate predictions. So, the use of 
artificial intelligence network is very important to predict the air vibration and peak particle velocity efficiently. Artificial neural network and fuzzy logic are the two most important concepts of artificial intelligence. They are useful in modeling or prediction of one or more variables. In this paper, an attempt has been made to predict the air and ground vibrations using fuzzy inference system and artificial neural network incorporating two variables, maximum charge per delay and the distance from blast to monitor which affect the ground vibration. Results are also compared with the values obtained from regression analysis and observed field data sets. Standard performance indices, such as root mean square error (RMSE) and variance -accounted-for (VAF) were used to compare the performance of the models results.

\section{FIELD EXPERIMENTAL PROCEDURE}

Assiut Cement Company (ACC) plant and quarries are located about $15 \mathrm{~km}$ North West of Assiut city. The limestone quarries have a three faces and lies west of the cement plant. Figure (1) shows a layout of Assiut cement quarry illustrating the locations of buildings and geophones in respect to the quarry face. The blasts in the present study have been planned to cover all the working faces on the upper and lower benches. That is to have a good average of the response of rocks along the path of the waves induced by the blasts. The height of the lower, middle, and upper faces equals 35,26 and $30 \mathrm{~m}$ respectively. Blasthole diameter ranges from $11.3 \mathrm{~cm}$ (4.5 inch) to 15 $\mathrm{cm}$ (6 inches) Other parameters benches include: burden $=6.5 \mathrm{~m}$, spacing $=8.5 \mathrm{~m}$, stemming length $=3 \mathrm{~m}$, subdrilling $=2 \mathrm{~m}$., single row and angle of inclination, $\alpha=$ 10o. Main explosive charge is ANFO while Ammonia Gelatin dynamite has been used as priming, bottom, and boosting charges. Usually the initiation type is NONEL system in one row with $25 \mathrm{~ms}$ surface delay interval.

Twenty three full scale production blasts have been carried out with number of blastholes per blast ranging from 10 to 20 . Weight of charge per delay ranged from 80 to $600 \mathrm{Kg}$ and total charge weight per blast ranged from 890 to $3270 \mathrm{Kg}$. The distance between the seismographs location to the center of the blast ranged from 326 to 1415 $\mathrm{m}$. The instruments used include one SSU-2000 DK seismograph system, $10 \mathrm{SSU}$ micro-seismographs, two data transfer cases, and two manual buttons. The SSU-2000 DK seismograph is a complete independent unit. Seismographs have been used to record the ground vibrations and air blast during each blast. Distance from each seismograph location to the center of the blast or center of the largest weight per delay has been measured.

Table (1) summarize a sample of measured data for each blast, including geophone number (G\#), distance from blast source to geophone, Maximum explosive charge /delay, peak overpressure (dB), peak particle velocity (PPV) in Three components longitudinal $(\mathrm{L})$, transverse $(\mathrm{T})$, and vertical $(\mathrm{V})$ according to the outputs of the seismogram. 


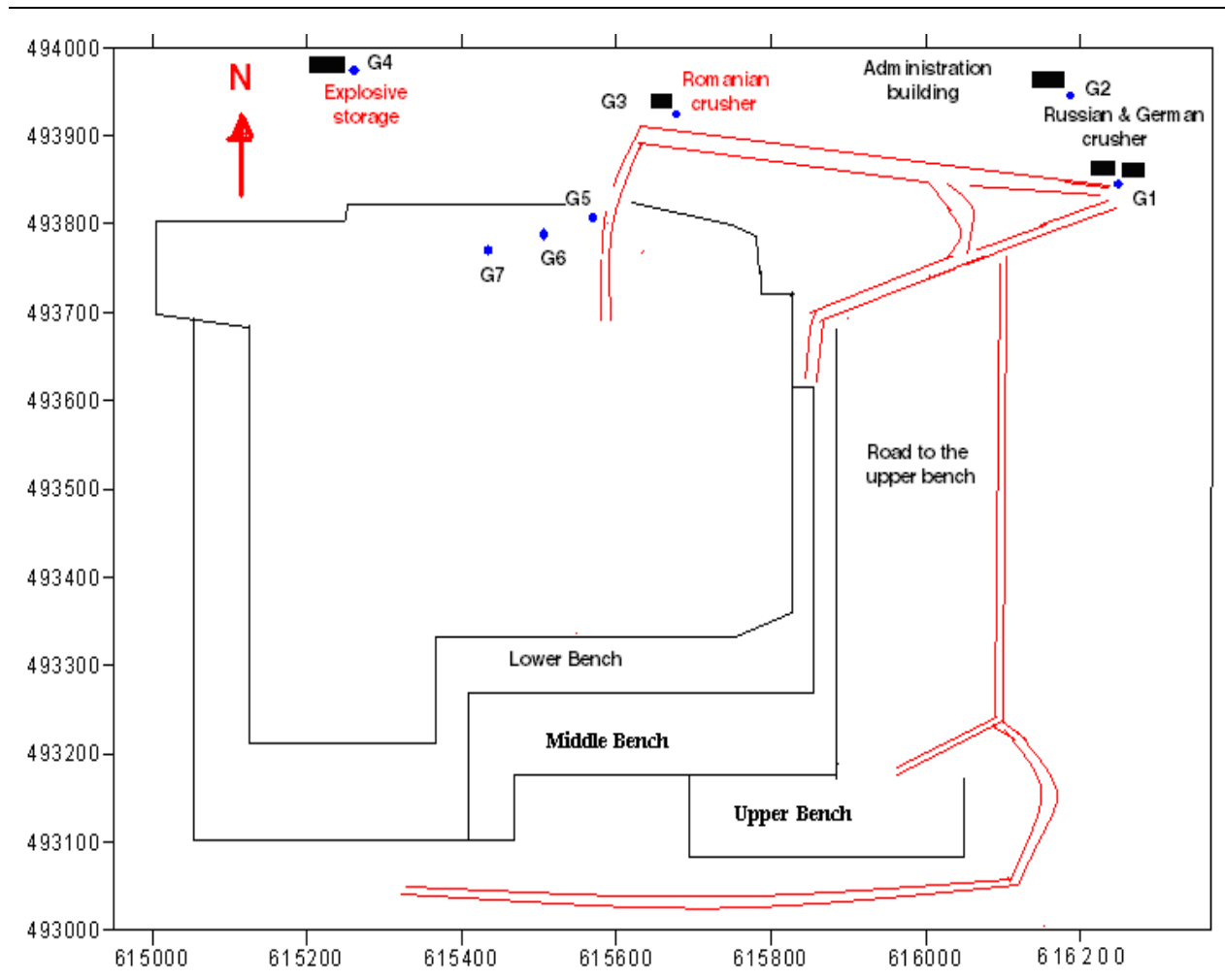

Fig. 1: Layout of the Limestone quarry at ACC

Table (1): Samples of the measured vibrations data.

\begin{tabular}{|c|c|c|c|c|c|c|c|}
\hline & \multirow{2}{*}{ G \# } & \multirow{2}{*}{$\begin{array}{c}\text { distance } \\
(\mathbf{m})\end{array}$} & $\begin{array}{c}\text { Max Charge/ } \\
\text { delay } \\
\end{array}$ & $(\mathbf{k g})$ & \multirow{2}{*}{$\begin{array}{c}\text { Peak } \\
\text { overpressure }\end{array}$} & \multicolumn{4}{|c|}{ PPV, mm / sec } \\
\cline { 5 - 8 }$(\mathbf{d B})$ & $\mathrm{L}$ & $\mathbf{T}$ & $\mathbf{V}$ & Resultant \\
\hline 4661 & 772.6 & 475 & 135 & 1.0 & 0.7 & 0.5 & 1.3 \\
\hline 4662 & 704.4 & 325 & 132 & 4.5 & 4.5 & 1.5 & 5.5 \\
\hline 4663 & 736.0 & 440 & 129 & 1.5 & 0.7 & 0.7 & 1.7 \\
\hline 4664 & 807.0 & 320 & 122 & 2.0 & 1.5 & 0.8 & 2.2 \\
\hline 2547 & 824.5 & 600 & 127 & 2.2 & 1.0 & 1.2 & 2.5 \\
\hline 4660 & 843.1 & 475 & 124 & 1.0 & 1.0 & 0.7 & 1.2 \\
\hline 4665 & 1121.3 & 450 & 118 & 0.7 & 1.2 & 1.0 & 1.5 \\
\hline 4653 & 1340.8 & 550 & 106 & 0.7 & 1.1 & 1.0 & 1.5 \\
\hline 4655 & 1195.6 & 475 & 124 & 1.5 & 1.5 & 0.7 & 2.0 \\
\hline
\end{tabular}




\section{TRADITIONAL REGRESSION ANALYSIS MODELS}

Many researchers, over the world, have studied ground vibrations originating from blasting and theoretical empirical analyses have been developed to explain the experimental data. At a given location, peak particle velocity (PPV) depends on the distance from the blast and the maximum charge per delay. Scaled distance (SD) is a dimensionless parameter for distance. It is derived as a combination of distance and charge weight influencing the generation of seismic and airblast energy. The scaleddistance concept vs. particle velocity and air overpressure is generally used for blast vibration prediction. Currently the most widely accepted propagation equation for ground and air vibration considering the damage to structures is in the form of $(3,4)$.

$$
V=K\left(R /{ }_{W} \beta\right)^{-\alpha}
$$

Where $\mathrm{V}$ is the peak particle velocity $(\mathrm{mm} / \mathrm{s})$ or peak overpressure $(\mathrm{dB}), \mathrm{k}$ and $\alpha$ are site constants to be determined by regression analysis; $\mathrm{R}$ is the distance of the measuring transducer from the blasting face $(\mathrm{m})$ and $\mathrm{W}$ is the maximum charge weight per delay $(\mathrm{kg})$. If the charge shape is cylindrical (charge length to diameter ratio greater than 6), the propagating wave front will be cylindrical. If the charge length to the diameter ratio is less than 6 or the distance from the shot is so far that the charge can be point source (or spherical). So, in this study according to the bench blasting features, square root scaling distance $(\beta=1 / 2)$ is selected to derive PPV prediction model (cylindrical wave propagation). While cube root scaling distance $(\beta=1 / 3)$ is selected to derive $\mathrm{dB}$ prediction model (spherical wave propagation).

\section{ARTIFICIAL NEURAL NETWORK (ANN)}

Artificial neural networks (ANNs) are a form of artificial intelligence that has proved to provide a high level of competency in solving many complex engineering problems that are beyond the computational capability of classical mathematics and traditional procedures. ANNs are able to detect similarities in inputs, even though a particular input may never have been seen previously. This property allows for excellent interpolation capabilities, especially when the input data are noisy (not exact). ANN can be defined as a data processing system consisting of a large number of simple, highly interconnected processing elements (artificial neurons) in an architecture inspired by the structure of the cerebral cortex of the brain (Tsoukalas and Uhrig, 1996).These processing elements are usually organized into a sequence of layers or slabs with full or random connections between the layers. The input layer is a buffer that presents data to the network. The following layer(s) is called the hidden layer(s) because it usually has no connection to the outside world. The output layer is the following layer in the network, which presents the output response to a given input. Typically the input, hidden, and output layers are designated the ith, jth, and kth layers, respectively. A typical neural network is "fully connected," which means that there is a connection between each of the neurons in any given layer with each of the neurons in the next layer $(2,5,6)$. 
Back-propagation artificial neural network a Feed-forward network is considered the most popular, effective and easy-to-learn model for complex, multilayered networks of the supervised learning techniques. The typical back-propagation network has an input layer, an output layer, and at least one hidden layer. There is no theoretical limit on the number of hidden layers but typically one or two hidden layers are enough for complex problems. Each layer is fully connected to the succeeding layer, as shown in Figure (2). In the back propagation training, the connection weights are adjusted to reduce the output error. In the initial state, the network begins with a small random set of connection weights. For the network to learn, a set of inputs is presented to the system and a set of out puts is calculated. A difference between the actual outputs and desired outputs is calculated and the connection weights are modified to reduce this difference (6).

Therefore, to simplify the process, the following is the scenario for the pth pattern in a feed-forward network with hidden layers (6) .

1. The ith node in the input layer holds a value of xpi for the pth pattern.

2. The net input to the jth node in the hidden layer for pattern $\mathrm{p}$ is

$$
\text { net pj }=\sum_{i}^{N} w \mathrm{ij} \text { opi }^{N}
$$

Where, wij is the weight from node $\mathrm{i}$ to node $\mathrm{j}$. The output from each unit $\mathrm{j}$ is the threshold function, $f \mathrm{j}$, which acts on the weighted sum. In this multilayer perceptron $f \mathrm{j}$ is the sigmoid function, defined as:

$$
\mathrm{f}(\text { net })=1 /(1+\mathrm{e}-\text { Knet }) ;(0<\mathrm{f}(\text { net })<1)
$$

Where, $\mathrm{k}$ is a constant that controls the spread of the function.

3. The output of the ith node in the hidden layer can also be defined as:

$$
\text { Opj = fj (netpj) }
$$

4. The net input to the kth node of the output layer is:

$$
\text { netk }=\sum_{j}^{N} \text { wkj xpj }
$$

Where, wkj is the weight values between the ith hidden layer and the kth output layer node.

5. Output of the kth node of the output layer can also be defined as:

$$
\text { Opk }=\mathrm{fk}(\text { netk) }
$$

6. If Ep is the error function for a pattern, $\mathrm{p}$, that is proportional to the square of difference between the actual and desired outputs for all the patterns to be learnt.

$$
\mathrm{Ep}=1 / 2 \sum_{k}^{N}(\mathrm{tpk}-\mathrm{opk}) 2
$$

Where, tpk and opk are the target and actual outputs for pattern $\mathrm{p}$ on node $\mathrm{k}$, respectively. 
$1^{\text {st }}$ hidden layer $2^{\text {nd }}$ hidden layer

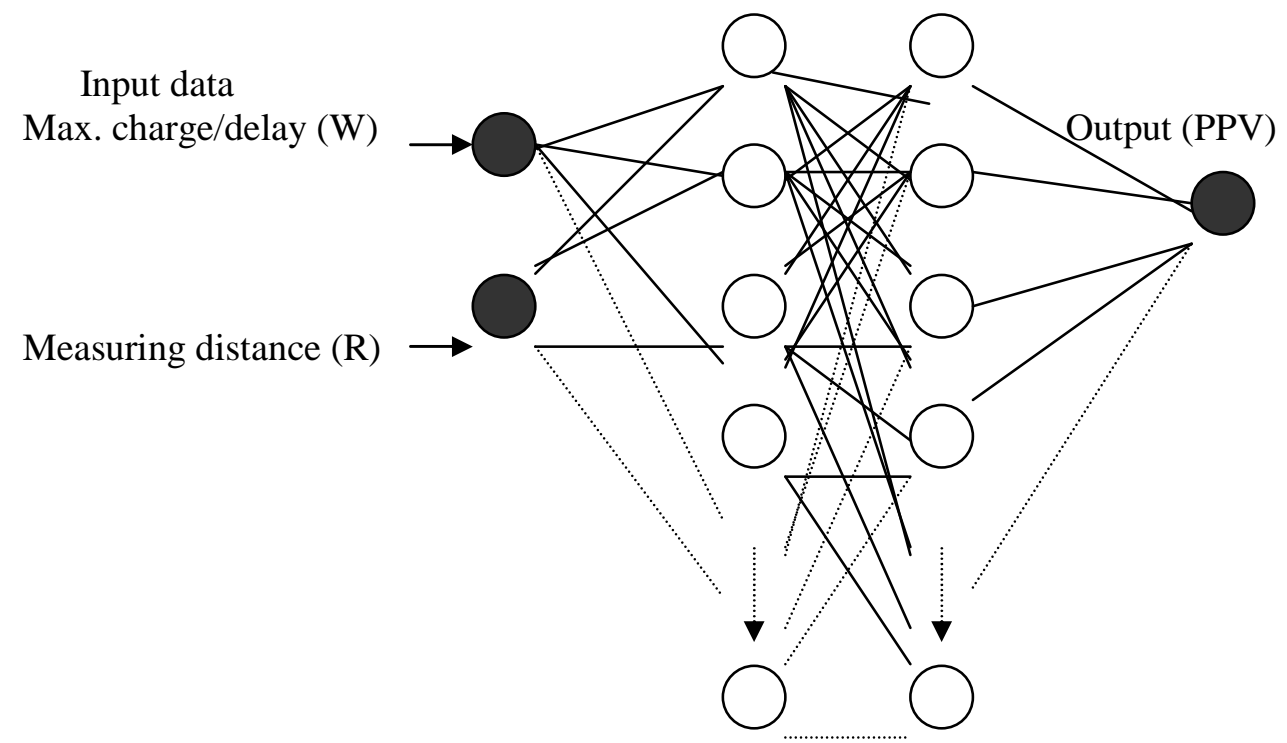

Fig. 2: Back propagation training ANN

\section{NETWORK ARCHITECTURE FOR ANN MODEL}

A feed-forward network is adopted here as this architecture is reported to be suitable for problems based on noisy database. Pattern matching is basically an input/output mapping problem. The closer the mapping, the better is the performance of network. Mapping is based on information, which is provided to the network as input; therefore, all the factors on which the output is believed to depend are provided to the network. The input pattern then performs feed-forward computations to calculate the output patterns. The output pattern is compared to the corresponding target patterns, and the summation of the squared error (MSE) is calculated. The error is then back propagated through the network using the gradient descent rule to modify the weights and minimize the summed squared error. Thus, a good mapping between input patterns and target patterns could be achieved, resulting in a network capable of predicting the target pattern for a given input pattern (6).

The models shape in this study is two input model, in this case the network model consists of the measuring distance and the maximum explosives/delay as the two-input parameters as shown in figure 2. About 136 data points were used to train the model, and 26 data points were used to test and validate the model.

\section{FUZZY SYSTEM}

Fuzzy systems are currently being used in a wide field of industrial and scientific applications. Fuzzy logic is a way to make machines more intelligent, enabling them to reason in a fuzzy manner like humans. Fuzzy models "think" the way as humans do (human-like thinking) and include verbal expressions instead of numbers. It is preferable when the mathematical problem is hard to derive, and when decisions have 
to be made with estimated values under incomplete information. First, it was proposed by Loutfi A. Zadeh in 1965 with the work "Fuzzy Set Theory" (Zadeh, 1965)(8). In 1974, E. H. Mamdani at the University of London published "Application to Control Problems" working on fuzzy logic. Later, this intelligence technique was applied in many areas. Fuzzy models can be seen as logical models which use "if-then" rules to establish qualitative relationships among the variables in the model. The rule-based nature of fuzzy models allows the use of information expressed in the form of natural language statements and consequently makes the models transparent to interpretation and analysis $(7,8)$.

Fuzzy sets and fuzzy logic is an extension of classical set theory and built around the central concept of a fuzzy set or membership function. Fuzzy set theory enables the processing of imprecise information by means of membership functions, in contrast to the classical set theory. The classical set (called crisp set) takes only two values: one, when an element belongs to the set; and zero, when it does not. In fuzzy set theory, an element can belong to a fuzzy set with its membership degree ranging from zero to one. The basis of fuzzy logic is to consider the system states in the form of subsets or fuzzy sets, each of which is labeled with words such as "low," "medium," "big," etc. A general fuzzy inference system basically consists of; fuzzification, knowledge base, a decision-making unit, and finally a defuzzification $(7,9)$, the fuzzy system is shown in figure 3 .

Fuzzification is the process where the crisp quantities are converted to fuzzy (crisp to fuzzy). Fuzzification converts each piece of input data to degrees of membership functions. There are three typical membership functions that are commonly used; these are triangular-shaped, gaussian-shaped and trapezoid-shaped. The knowledge base comprises a data base and a rule base. Membership functions of the fuzzy sets are contained in the data base. Fuzzy rule base contains rules that include all possible fuzzy relations between inputs and outputs. These rules are expressed in the IF-THEN format with antecedents and consequents, respectively, connected by interchangeably with the logical "AND" or "OR" conjunction. The decision-making unit also known fuzzy inference engine is the essential part of a fuzzy rule based system. Fuzzy inference engine takes into account all the fuzzy rules in the fuzzy rule base and learns how to transform a set of inputs to corresponding outputs. It employs IF-THEN rules from the rule base to infer the output by a fuzzy reasoning method. Fuzzy reasoning (also known as approximate reasoning) is an inference procedure used to derive conclusions from a set of fuzzy IF-THEN rules and from one or more given conditions $(7,10)$.

The result of each fuzzy inference is clearly a fuzzy set. This set can be converted to a single real number by a defuzzification method. Defuzzification converts the resulting fuzzy outputs from the fuzzy inference engine to a number. There are many defuzzification methods such as centre of gravity (COG) (centroid), bisector of area (BOA), mean of maxima (MOM), leftmost maximum (LM), rightmost maximum (RM), and so on. the most frequently used method is called a centroid (also called center of area or center of gravity) method. There are two main types of fuzzy inference methods which are frequently used in the application of the fuzzy modeling and forecasting. The first is Mamdani's fuzzy inference method introduced by Mamdani and Assilian. Another well-known inference method is the so-called Sugeno 
or Takagi-Sugeno-Kang (TSK) method of fuzzy inference process introduced by Takagi and Sugeno $(5,7,10)$.

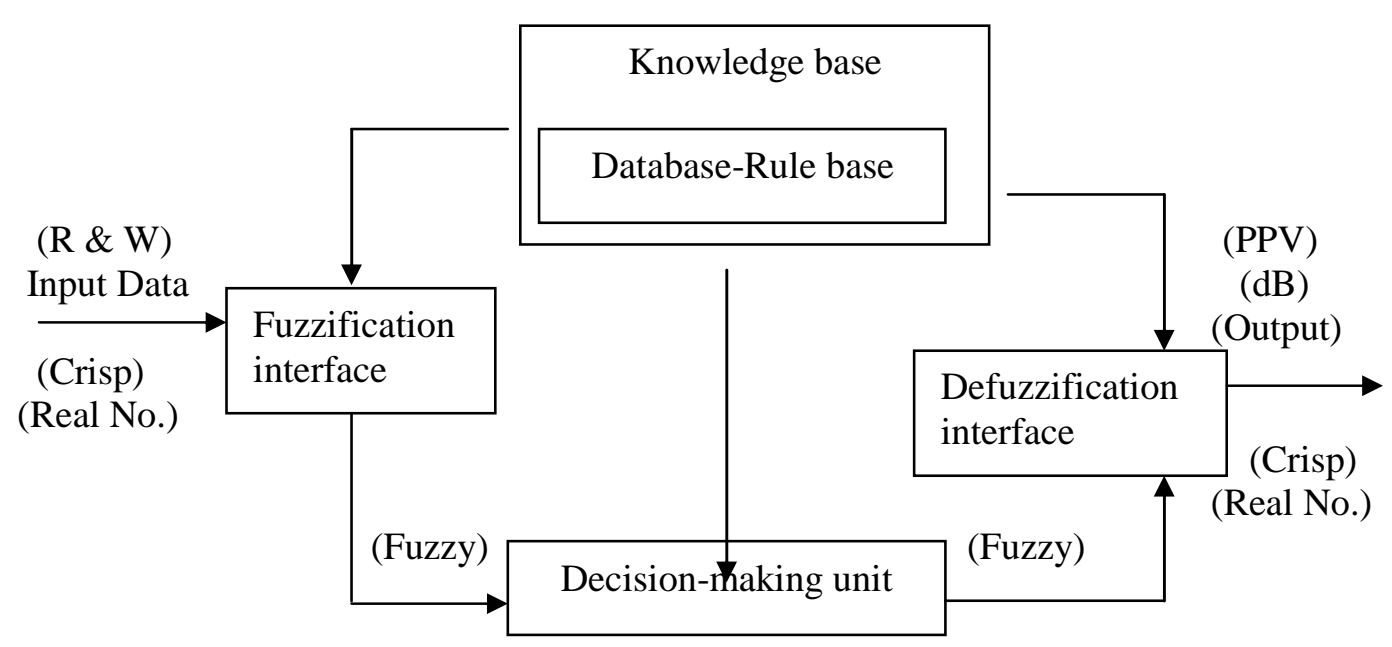

Fig.3: A typical Fuzzy System for Fuzzy Logic Modeling Process.

\section{FUZZY MODELING}

In the present work only Takagi-Sugeno-Kang (TSK) fuzzy model has been considered. The present fuzzy models for the prediction of PPV and dB have two inputs and one output variable. About 136 data points were used for prediction models, the input variables are the distance from blast face to vibration monitor and charge weight per while PPV and dB are taken as the output variables. About 26 data points were selected to test and validate the models. The Gaussian membership function has been chosen in the present study because of its simplicity and computational efficiency. The membership functions of inputs for PPV and dB models are shown in figure 4 and 5 respectively. The relationships between inputs and output are represented in the form of IF-THEN rules. The number of input variables and their associated membership functions determine the number of rules. In this study the number of membership functions of the first and second inputs is 5 and 11 for PPV prediction model. But the number of membership functions for the first and the second inputs is 7 and 7 for $\mathrm{dB}$ prediction model. This yields a total number of rules (5x11) equal to 55 and (7x7) equal to 49 for PPV and dB models respectively. 

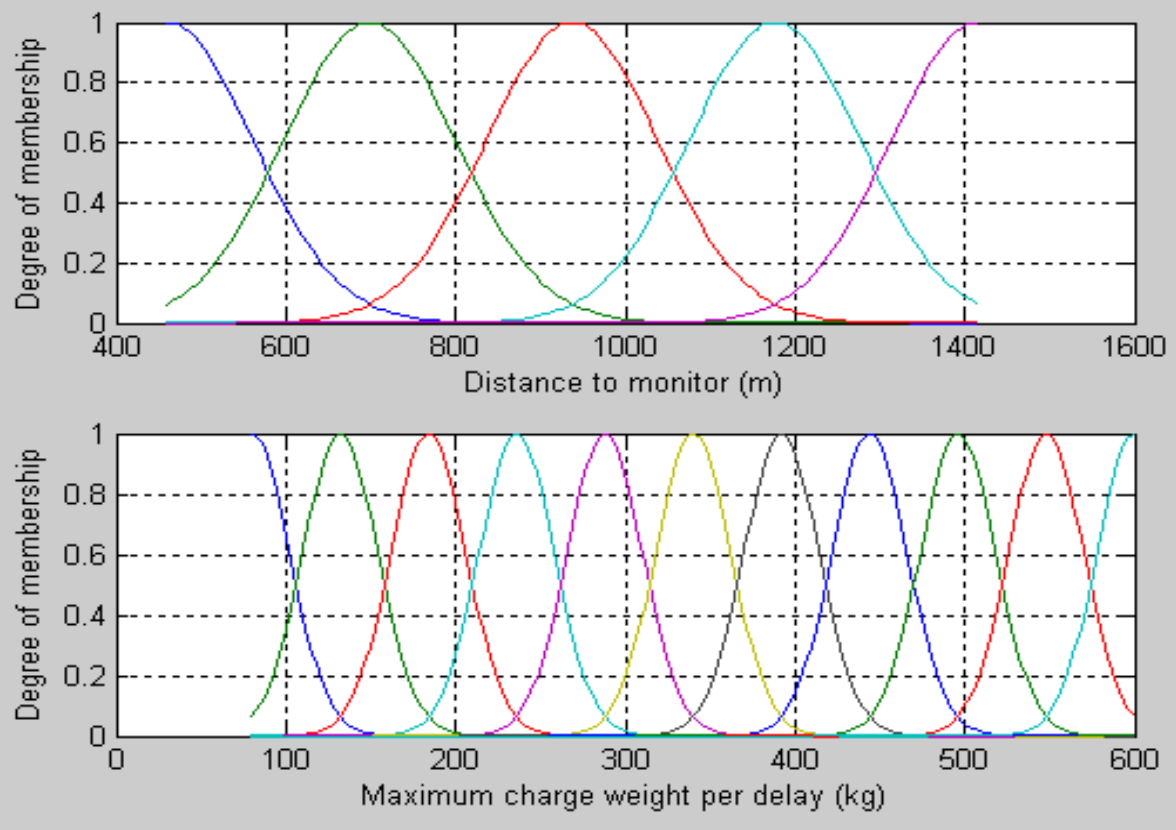

Fig. 4: Membership functions of PPV model inputs
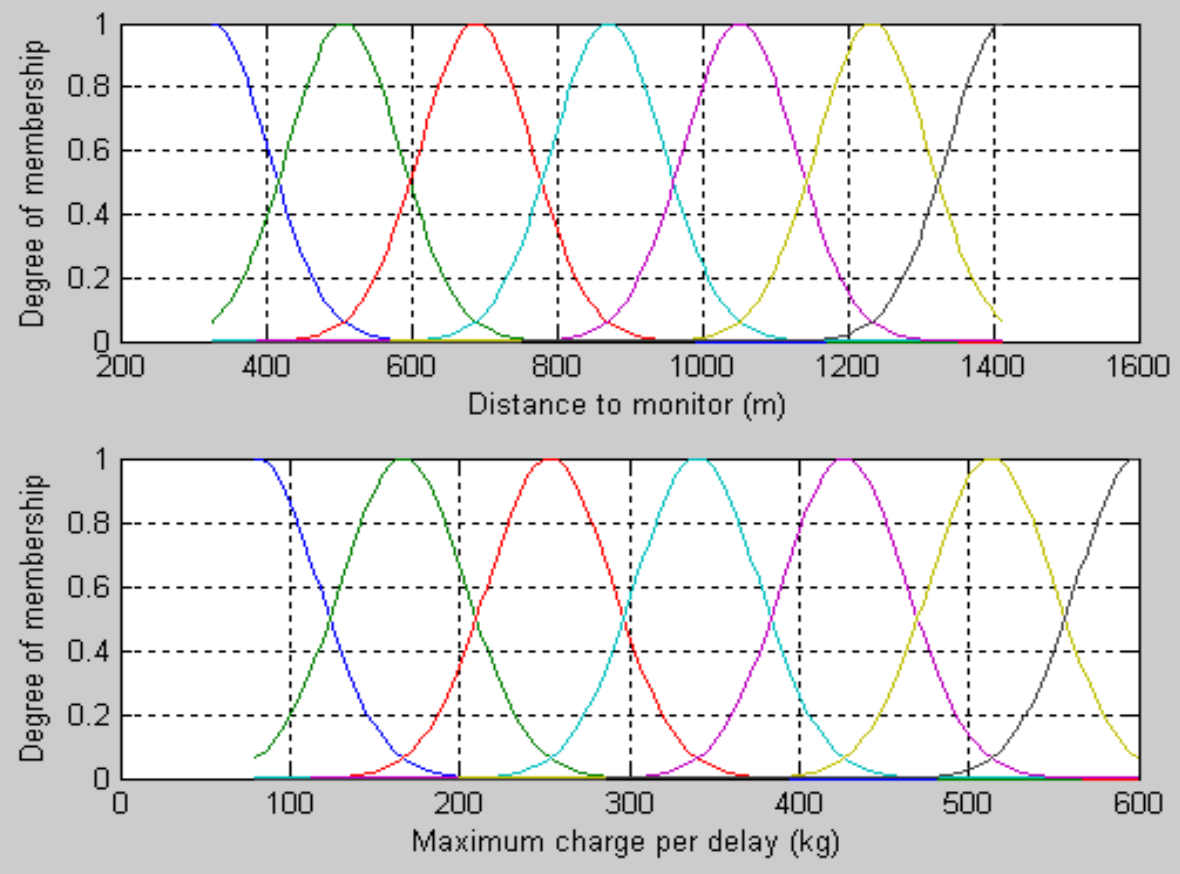

Fig. 5: Membership functions of $\mathrm{dB}$ model inputs 


\section{RESULTS AND DISCUSSIONS:}

\subsection{Statistical Method Prediction:}

Statistical analysis was applied for the data sets to obtain the models of propagation law to predict PPV and $\mathrm{dB}$. These conventional models is defined by the relationship between PPV and $\mathrm{dB}$ with scaled distance, the resulted models are:

$$
\mathrm{PPV}=37.07(\mathrm{R} / \mathrm{W} 1 / 2)-0.843
$$

With correlation coefficient $\mathrm{R}=-0.66$

$$
\mathrm{dB}=218.28(\mathrm{R} / \mathrm{W} 1 / 3)-0.121
$$

With correlation coefficient $\mathrm{R}=-0.55$

Where $(\mathrm{R} / \mathrm{W} 1 / 2)$ and $(\mathrm{R} / \mathrm{W} 1 / 3)$ are scaled distance for PPV and $\mathrm{dB}$ models. According to correlation coefficient the two models indicate that there are medium intensity relationships of the two models.

\subsection{Artificial Intelligence Prediction:}

A satisfactory well-trained model of ANN was obtained after a series of neural network training. The suggested ANN architectures for the models are two hidden layers, two input layers and one output layer with different nodes. The best training sessions of the suggested models of ANN for prediction of PPV and dB are shown in Table 2. Different number neurons in the hidden layers and training cycles (No. of epochs) as well as values of learning rate and momentum were selected to reach the least error. Figure 6 and 7 clear the training part of PPV and dB models with correlation coefficients equal 0.97 and 0.96 respectively.

A well-trained fuzzy model was obtained after a series of Training conditions. The best training models for fuzzy inference system to be used for predicting PPV and $\mathrm{dB}$ reach correlation coefficient of 0.95 and 0.93 respectively and are presented in table 3 . To assess the performance of the prediction models used in this study the following performance indices were selected to evaluate namely, the variance accounted for $(\mathrm{VAF})$ and the root mean square error (RMSE):

$$
\begin{aligned}
& \mathrm{VAF}=\left[1-\frac{\operatorname{var}\left(y_{i}-\hat{y}_{i}\right)}{\operatorname{var}\left(y_{i}\right)}\right] \times 100 \% \\
& \mathrm{RMSE}=\sqrt{\frac{1}{N} \sum_{i=1}^{N}\left(y_{i}-\hat{y}_{i}\right)^{2}}
\end{aligned}
$$

Where var denotes the variance, $\mathrm{y}$ is the measured value, $\mathrm{y}^{\wedge}$ is the predicted value, and $\mathrm{N}$ is the number of the samples.

The performance indices are interpreted as follows: the higher the VAF and the lower RSME, the better the model performs. For instance, if the VAF is 100\% and RMSE is 0 , then the model will be excellent (11).

From the comparison in table 4, The VAF and the RMSE indices were calculated for PPV models as $3.23 \%-0.45,78.39 \%-0.21$, and $87 \%-0.17$ for 
statistical, ANN, and fuzzy models respectively. Also, The VAF and the RMSE were calculated for $\mathrm{dB}$ models as $99.83 \%-4.92,99.94 \%-2.9$, and $99.95 \%-2.71$ for statistical, ANN, and fuzzy models respectively. As can be seen from these results, the prediction accuracy in terms of both indices for the ANN and fuzzy models is better than for statistical model. In accordance to the values of performance indices, fuzzy models give slightly better than ANN models. It indicates that the prediction of ground vibration using fuzzy model is more generalization and validation than ANN although the ANN models give a higher correlation coefficients in the training parts. Figure 8 and 9 clarify the comparison between recorded and predicted values for all predictors.

\section{Table (2): Training Parameters for Selected ANN Models.}

\begin{tabular}{|c|c|c|c|c|c|c|c|c|c|c|}
\hline $\begin{array}{c}\text { Neural } \\
\text { Network } \\
\text { Model } \\
\text { (ANN) }\end{array}$ & 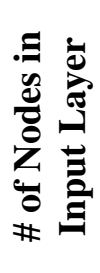 & 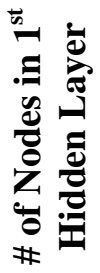 & 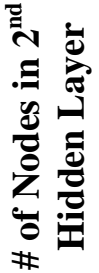 & 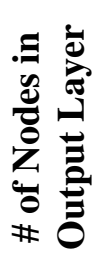 & 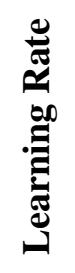 & 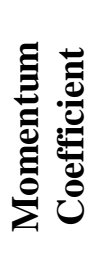 & 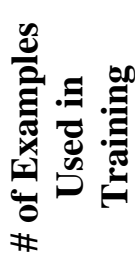 & 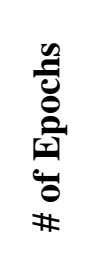 & 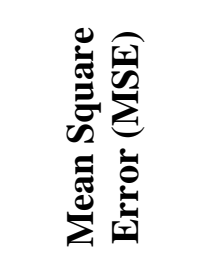 & ن⿺辶 \\
\hline $\begin{array}{c}\text { PPV } \\
\text { Model }\end{array}$ & 2 & 9 & 8 & 1 & 0.2 & 0.9 & 136 & 2500 & 0.00127577 & 0.9 \\
\hline $\begin{array}{c}\mathrm{dB} \\
\text { Model }\end{array}$ & 2 & 8 & 8 & 1 & 0.5 & 0.9 & 136 & 7000 & 0.00519543 & \\
\hline
\end{tabular}

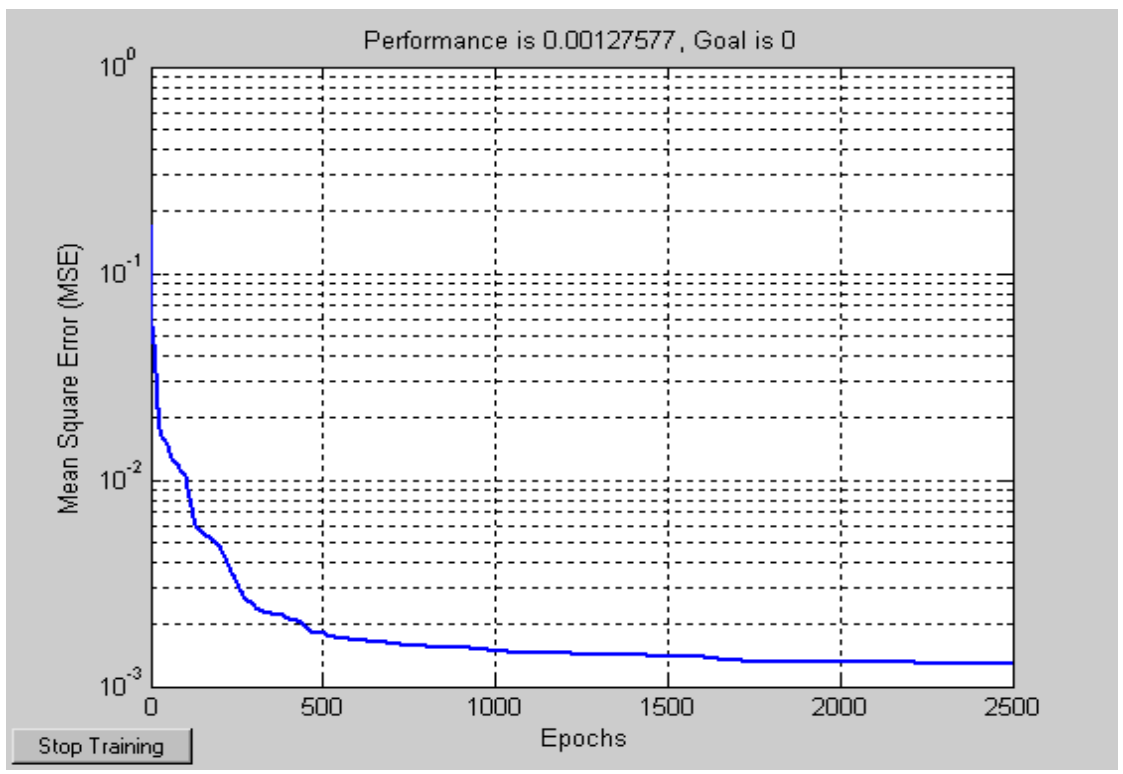

Fig. 6: Training part of PPV model for error minimization 


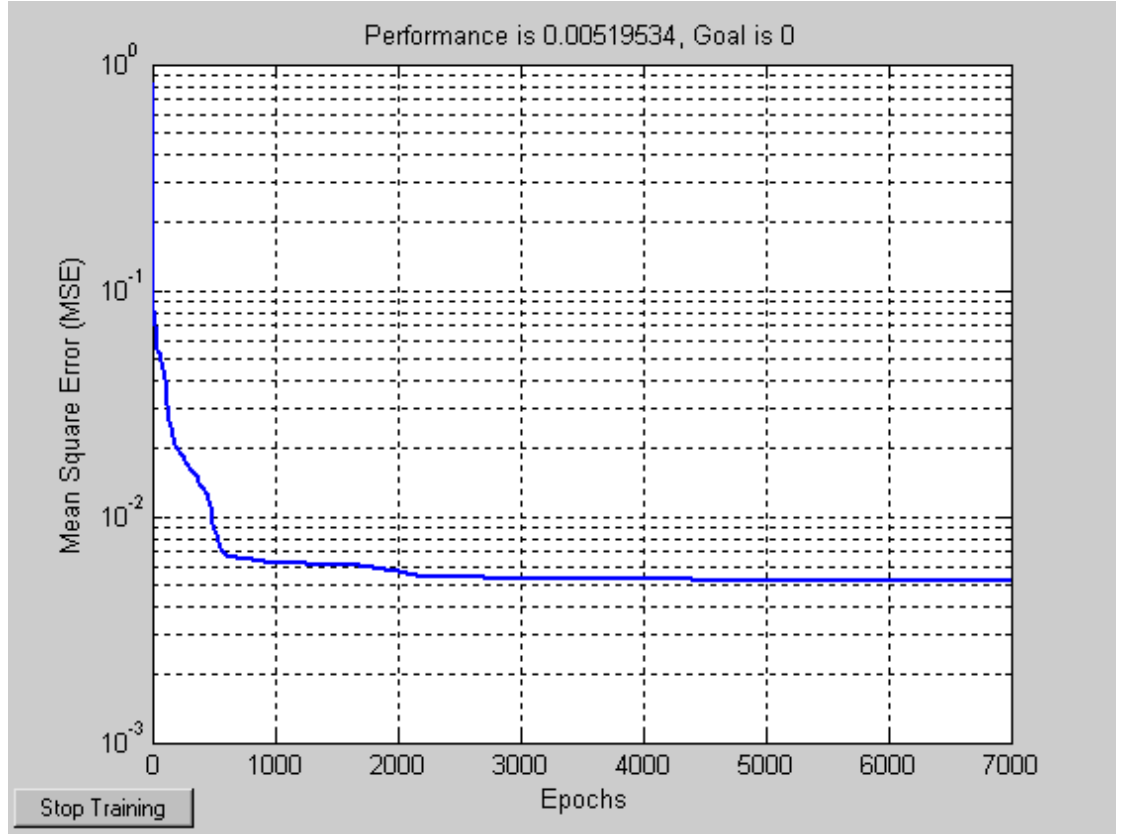

Fig. 7: Training part of $\mathrm{dB}$ model for error minimization

Table (3): Training Parameters for Selected fuzzy Models.

\begin{tabular}{|c|c|c|c|c|c|c|c|}
\hline $\begin{array}{c}\text { Fuzzy } \\
\text { Inference } \\
\text { System } \\
\text { Model }\end{array}$ & 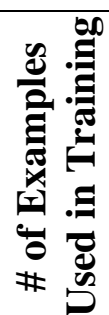 & 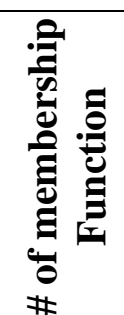 & 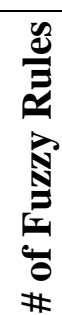 & 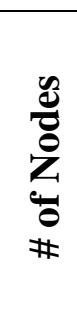 & 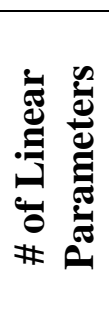 & 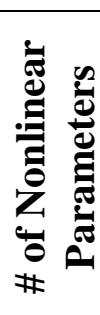 & 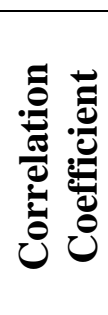 \\
\hline $\begin{array}{c}\text { PPV } \\
\text { Model }\end{array}$ & 136 & {$[5,11]$} & 55 & 147 & 165 & 32 & 0.95 \\
\hline $\begin{array}{c}\mathrm{dB} \\
\text { Model }\end{array}$ & 136 & {$[7,7]$} & 49 & 136 & 147 & 28 & 0.93 \\
\hline
\end{tabular}




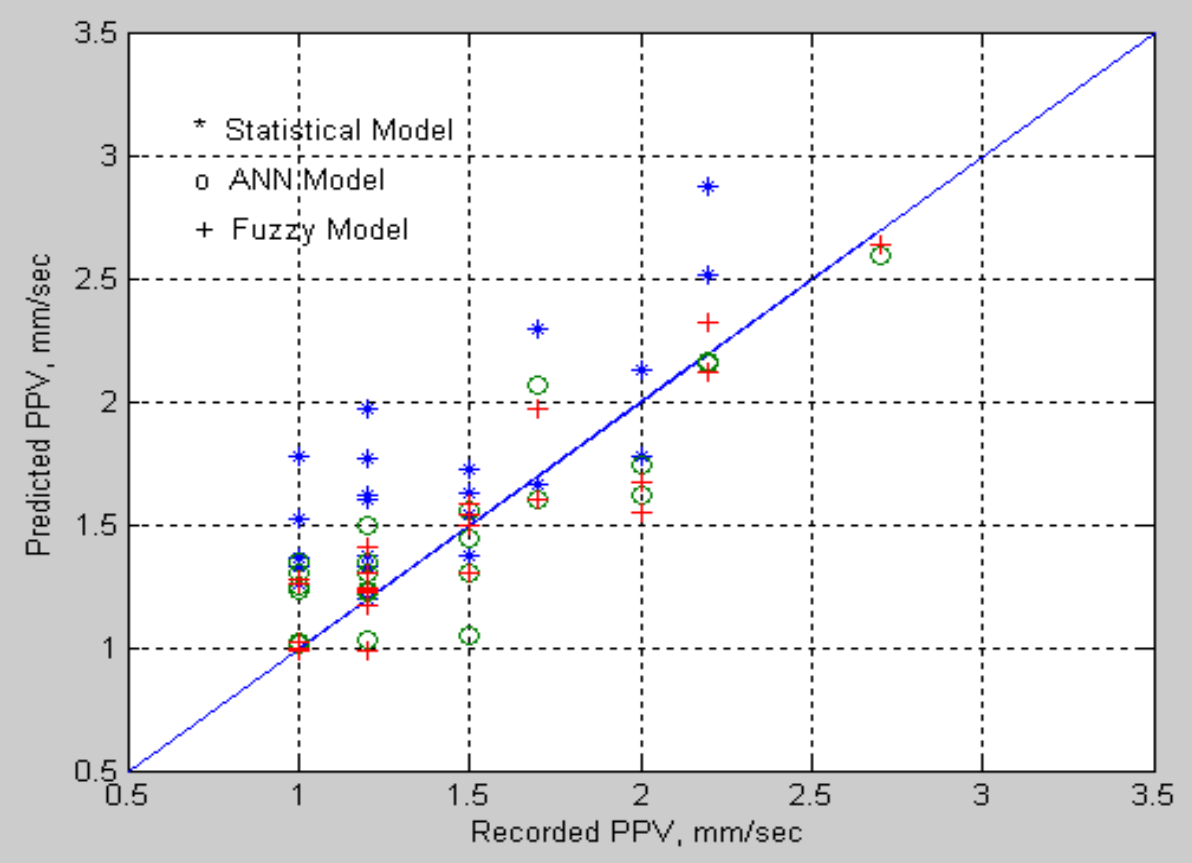

Fig. 8: Recorded vs. predicted PPV for the different models

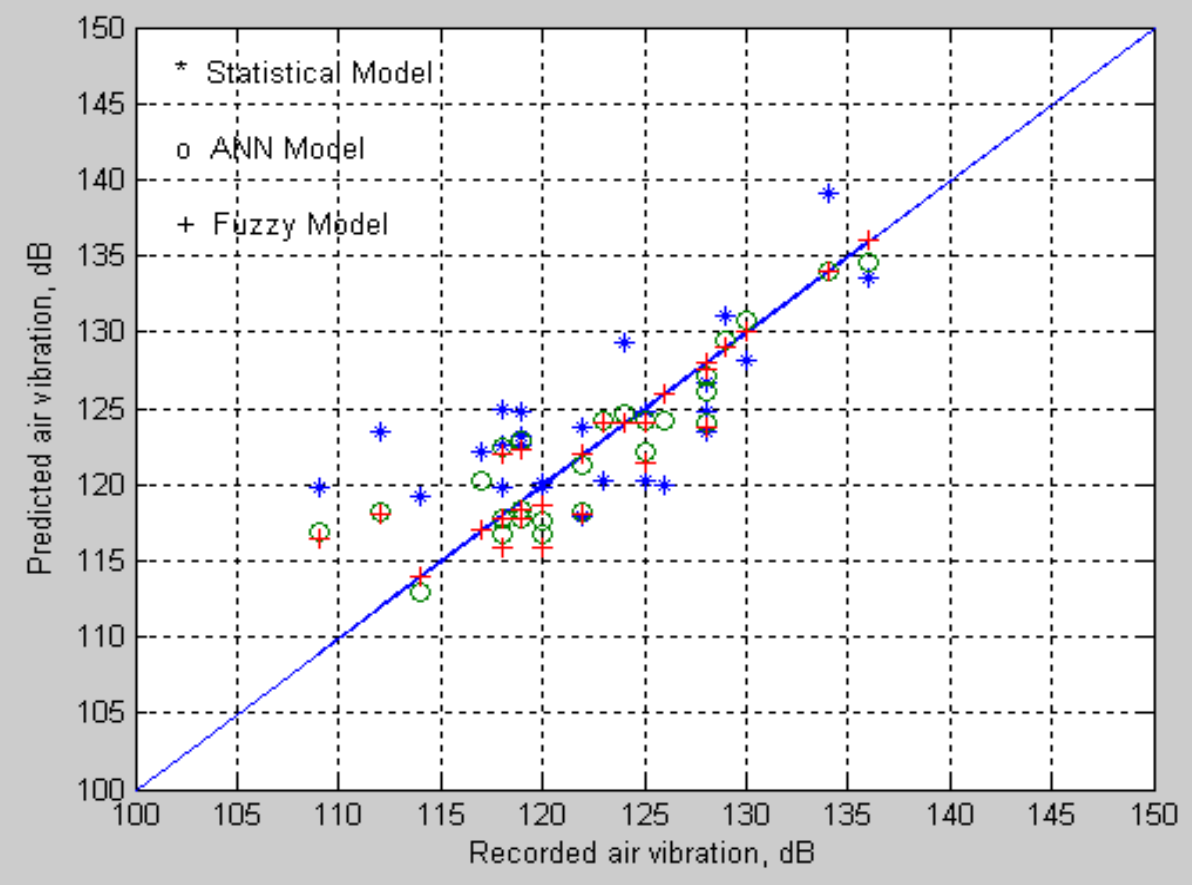

The Fig. 9: Recorded vs. predicted dB for the different models 
Table (4): Comparison between recorded and predicted values of peak

particle velocity (PPV) and air vibration (dB) for Models predictors.

\begin{tabular}{|c|c|c|c|c|c|c|c|c|}
\hline $\begin{array}{l}\dot{0} \\
\dot{Z} \\
\stackrel{\tilde{y}}{*}\end{array}$ & 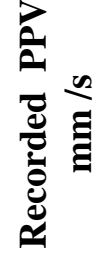 & 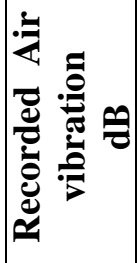 & 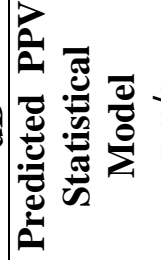 & 鹿 & 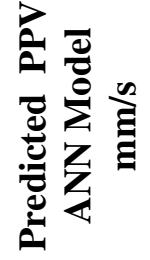 & 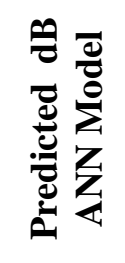 & 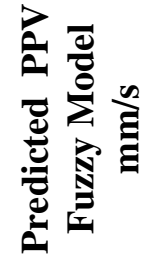 & 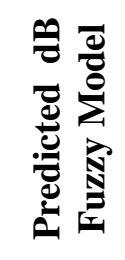 \\
\hline 1 & 2.00 & 128.0 & 1.78 & 124.7 & 1.74 & 127.1 & 1.67 & 128.0 \\
\hline 2 & 1.70 & 128.0 & 1.66 & 123.5 & 1.60 & 124.0 & 1.60 & 123.8 \\
\hline 3 & 1.20 & 122.0 & 1.20 & 117.9 & 1.22 & 121.2 & 1.22 & 122.0 \\
\hline 4 & 1.50 & 119.0 & 1.63 & 123.2 & 1.56 & 122.9 & 1.58 & 122.3 \\
\hline 5 & 1.50 & 117.0 & 1.54 & 122.1 & 1.44 & 120.3 & 1.54 & 117.0 \\
\hline 6 & 2.20 & 136.0 & 2.87 & 133.6 & 2.15 & 134.6 & 2.32 & 136.0 \\
\hline 7 & 2.20 & 129.0 & 2.51 & 131.1 & 2.16 & 129.5 & 2.12 & 129.0 \\
\hline 8 & 1.20 & 125.0 & 1.37 & 120.2 & 1.30 & 124.2 & 1.30 & 124.0 \\
\hline 9 & 1.50 & 123.0 & 1.37 & 120.2 & 1.30 & 124.2 & 1.30 & 124.0 \\
\hline 10 & 2.70 & 134.0 & 3.81 & 139.2 & 2.59 & 134.0 & 2.64 & 134.0 \\
\hline 11 & 1.70 & 124.0 & 2.29 & 129.4 & 2.07 & 124.7 & 1.97 & 124.0 \\
\hline 12 & 1.00 & 126.0 & 1.36 & 120.0 & 1.30 & 124.2 & 1.28 & 126.0 \\
\hline 13 & 2.00 & 130.0 & 2.13 & 128.1 & 1.62 & 130.8 & 1.55 & 130.0 \\
\hline 14 & 1.20 & 128.0 & 1.97 & 126.7 & 1.50 & 126.1 & 1.41 & 127.6 \\
\hline 15 & 1.00 & 120.0 & 1.33 & 119.8 & 1.23 & 116.8 & 0.99 & 115.9 \\
\hline 16 & 1.20 & 118.0 & 1.33 & 119.8 & 1.23 & 116.8 & 0.99 & 115.9 \\
\hline 17 & 1.20 & 125.0 & 1.77 & 124.7 & 1.35 & 122.2 & 1.24 & 121.4 \\
\hline 18 & 1.00 & 118.0 & 1.78 & 124.9 & 1.35 & 122.4 & 1.26 & 122.0 \\
\hline 19 & 1.00 & 120.0 & 1.36 & 120.1 & 1.25 & 117.6 & 1.02 & 118.69 \\
\hline 20 & 1.00 & 109.0 & 1.33 & 119.8 & 1.23 & 116.9 & 0.99 & 116.4 \\
\hline 21 & 1.50 & 119.0 & 1.72 & 124.7 & 1.05 & 118.4 & 1.50 & 118.4 \\
\hline 22 & 1.00 & 118.0 & 1.52 & 122.6 & 1.02 & 117.7 & 1.00 & 117.7 \\
\hline 23 & 1.00 & 119.0 & 1.52 & 122.6 & 1.02 & 117.7 & 1.00 & 117.7 \\
\hline 24 & 1.00 & 114.0 & 1.26 & 119.3 & 1.01 & 113.0 & 1.00 & 114.0 \\
\hline 25 & 1.20 & 122.0 & 1.62 & 123.7 & 1.03 & 118.2 & 1.23 & 118.1 \\
\hline 26 & 1.20 & 112.0 & 1.60 & 123.5 & 1.03 & 118.2 & 1.17 & 118.0 \\
\hline RMSE & & & 0.45 & 4.92 & 0.21 & 2.90 & 0.17 & 2.71 \\
\hline VAF & & & $3.23 \%$ & $99.83 \%$ & $78.39 \%$ & $99.94 \%$ & $87.00 \%$ & $99.95 \%$ \\
\hline
\end{tabular}

\section{CONCLUSION}

By using 136 data sets of Peak particle velocity and air vibration (dB), models predictions of traditional statistics, ANN and fuzzy were developed. The models were verified, and compared by using new 26 data sets of vibrations. Performance indices such as variance accounted for (VAF) and the root mean square error (RMSE) were calculated to compare the models performance. These indices revealed that, the ANN and fuzzy models have accurate prediction than that of traditional regression equations. 
Also, the fuzzy model exhibited slightly higher prediction performance than ANN model based on the performance indices. So, from this investigation for safety, Assiut Cement Company must adopt these models of artificial intelligence to predict precisely the damage induced by blasting in their quarry.

\section{REFERENCES}

1- Douglas E. "An Investigation of Blasting Criteria For Structural and Ground Vibrations" M.Sc. Thesis Presented, Ohio University, Ohio University, June, 1989.

2- Singh T. N. and Singh V., "An Intelligent Approach to Prediction and Control Ground Vibration in Mines", Geotechnical and Geological Engineering Journal, Vol.23, 2004, pp. 249-262.

3- Dowding CH. "Blast Vibration Monitoring and Control", Englewood Cliffs, NJ: Prentice-Hall; 1985.

4- Elseman I. Abdel-Rasoul, "Measurement and Analysis of The Effect of Ground Vibrations Induced by Blasting at The Limestone Quarries of The Egyptian Cement Company", ICEHM2000, Cairo University, Egypt, September, 2000, pp. 54- 71 .

5- Singh T. N., Kanchan R., Verma A. K., and Saigal K., "A Comparative Study of ANN and Neuro-Fuzzy for The Prediction of Dynamic Constant of Rockmass", J. Earth Syst. Sci., Febraury 2005, pp. 75-86.

6- Mohamed M.T., "Artificial neural network for prediction and control of blasting vibrations in Assiut (Egypt) limestone quarry”, Int J Rock Mech Mining Sci, Mining Sciences 46 (2009) 426-431.

7- Sever C.,"Artificial Neural Networks and Fuzzy Logic Applications in Modeling the Compressive Strength of Portland Cement", M.Sc. thesis, ,Izmir Institute of Technology, Izmir, Turkey, December, 2004.

8- Zadeh, L.A., "Fuzzy sets. Information and Control”, 1965; 8: 338 - 353.

9- Ross T. J., "Fuzzy logic with Engineering Applications", Second Edition. England: John Wiley \& Sons, 2004.

10- Abdullah F., Cengiz K., Türker H., "Fuzzy Model for The Prediction of Blast induced Ground Vibration in Quarry Operations in Istanbul", Manuscript Number: IJRMMS-D 08-00246, 2009.

11- Yusuf E., "The use of neural networks for the prediction of swell pressure", Geomechanics and Engineering, Vol. 1, No. 1 (2009), pp. 75-84 
أداء المنطق الضبابى الهلامى والشبكة العصبية الأصطناعية فى التنبؤ بالأهتزازات

\section{الهوائية والأرضية}

\section{مصطفى طنطاوى محمد}

\section{قسم هندة التعدين والفلزات - كلية الهندة - جامعة أسيوط}

التتبؤ بالأهنزازات الهوائية والأرضية هى مشكلة كبرى فى أنشطة تفجير الصخور. هدف هذه الدراسة

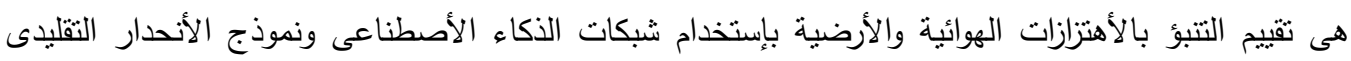
الأحصائى. لذلك تم إنثاء نماذج المنطق الضبابى الهلامى والثبكة العصبية الأصطناعية للتنبؤ بسرعة حبيبات

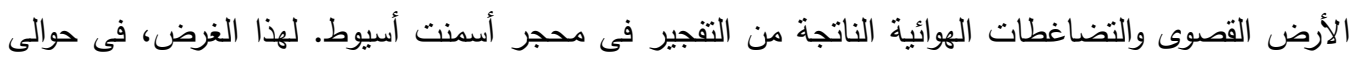
136 ضربية تفجير عند مسافات مختلفة تم قباس سرعة الحبييات القصوى والأهتزازات الهوائية ووزن شحنة الكفرقعات لكل زمن تأخير وإستخدامها فى تدريب نماذج التتبؤ. وتم إستخدام قياسات 26 ضربية جديدة لإختبار

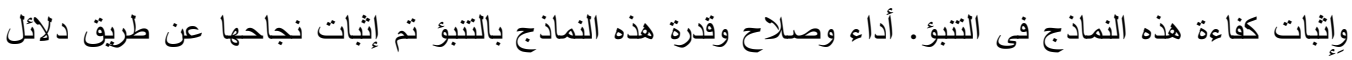
الأداء الأحصائية. هذه الدلائل هى تبرير الأختلاف وخطأ جذر منوسط المربعات. نتائج النماذج أكدت أن تقنتيات شبكات الذكاء الصناعية تستطيع التتبؤ بدقة وكفاءة اعلى بالأهتزازات الهوائية والأرضية بالمقارنة بالتحليل

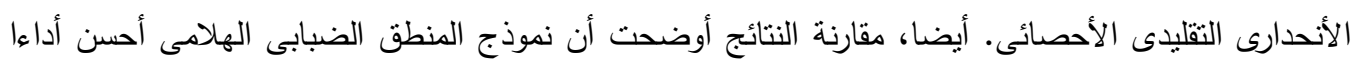
بعض الثىء عن الثبكة العصبية الأصطناعية فى التتبو بالأهنزازات الهوائية والأرضية. 